\title{
ELECTROMYOGRAPHY OF THE ORAL PHASE OF DEGLUTITION IN THE RHESUS MONKEY (MACACA MULATTA)
}

\author{
J. A. McNamara, JR. and R. E. Moyers \\ Department of Anatomy and Center for Human Growth and Development, \\ The University of Michigan, Ann Arbor, Michigan 48104, U.S.A.
}

\begin{abstract}
Summary-Patterns of activity of selected muscle groups which function during the oral phase of swallowing were analysed electromyographically in 33 monkeys (Macaca mulatta) during a total of 113 recording sessions. Salivary, water and masticatory swallows were studied. The activity of the suprahyoid muscle group was relatively constant in each animal during all types of swallows. However, three patterns of muscle activity of the other masticatory muscles were identified. In the first pattern (pattern $A$ ), the suprahyoids usually fired concurrently with the superior head of the lateral pterygoid muscle with little or no elevator activity evident. In the second pattern (pattern $B$ ), the temporal muscle, masseter muscle and superior head of the lateral pterygoid muscle fired concurrently with the suprahyoids. In the third pattern (pattern $C$ ), elevator and lateral pterygoid activity preceded the suprahyoid burst. The inferior head of the lateral pterygoid was not active in any swallowing pattern. About 60-70 per cent of the salivary swallows were of pattern $A$. Most water-swallows were of patterns $B$ and $C$, while those swallows associated with mastication were entirely of pattern $C$.
\end{abstract}

\section{INTRODUCTION}

SWALLOWING is a complex pattern of muscle activity which is based upon an integration of both learned and unlearned reflexes. DoTY (1968) divides deglutition into three sequential components according to their respective neural control systems: the buccopharyngeal, the oesopharyngeal and the gastroesophageal phases. In the present study, selected muscle groups active during the first phase of swallowing have been examined.

Swallowing is initiated by appropriate stimulation of the fifth, ninth, or tenth cranial nerves or by input from specific cortical, hypothalamic or midbrain areas (STOREY, 1967). The glossopharyngeal nerve, the pharyngeal branch of the vagus nerve and the superior laryngeal nerve, which innervate the base of the tongue, the faucal pillars, the larynx and the posterior pharyngeal areas, are the primary afferent nerves for the reflex initiation of swallowing. Impulses trigger the neurons of the swallowing centre, which are located in the lateral portion of the reticular formation (Miller and Sherrington, 1916; Doty, Richmond and Storey, 1967). The swallowing centre is a functional neuronal grouping which, when stimulated, produces the appropriate excitatory and inhibitory sequence of motor neuron activity (DOTY et al., 1967). The swallow is a synergy involving motor nuclei from the fifth to the twelfth cranial nerves. 
Swallowing has been studied and described in many different ways, depending upon the circumstances and constraints of the investigative situation and upon the species. For example, dentists, speech therapists and other researchers have conducted clinical studies of human swallows (e.g. Rix, 1946; Tulley, 1953; Findlay and KiLPatricK, 1960; Cleall, 1965; Hanson, 1967; Fletcher, 1971; Hrycyshyn and Basmajian, 1972). Swallows associated with the consumption of water and saliva, and to a lesser extent those associated with mastication, have been monitored. MoYers (1964a) notes that four types of swallows have been differentiated during the clinical studies of man: the command swallow of water, the command swallow of saliva, the unconscious salivary swallow and the unconscious swallow during mastication.

Most animal studies have used anaesthetized or decerebrated cats, dogs, monkeys or rabbits. The stimulation of specific anatomic areas is effective in eliciting the swallowing reflex. The application of touch or fluids to the palate, the pharynx, the base of the tongue, the epiglottis or to the interior of the larynx evokes deglutition in these species (Waller and Prevost, 1870; Kahn, 1903; Miller and Sherrington, 1916; DotY and BosMA, 1956). Electrophysiological stimulation of peripheral nerves or of areas within the central nervous system provokes similar muscle synergies (Beevor and Horsley, 1888; Rylant, 1943; Doty, 1951; Doty and Bosma, 1956; DoTY et al., 1967).

Difficulties arise, however, in comparing the results of clinical and laboratory studies and in comparing studies which utilize different species. Doty and Bosma (1956) note that inter- and intra-species variations exist in the participation of the musculature during swallowing. In addition, swallows elicited under varying conditions (i.e. anaesthesia vs no anaesthesia) are not necessarily similar.

The purpose of the current study is to investigate certain patterns of muscular activity in the rhesus monkey during the oral phase of deglutition, under conditions similar to those used in clinical studies of man.

\section{MATERIALS AND METHODS}

Thirty-three monkeys (Macaca mulatta), 6 months- 8 yr of agc, werc monitored serially in a total of 113 electromyographic recording sessions. Thirteen animals were monitored on five occasions, two animals on four, seven animals on three, eight animals on two occasions, and three animals on one occasion. One to four weeks elapsed between recording sessions on the same animal. From 1 to $2.5 \mathrm{hr}$ were used for each session.

Each animal was anaesthetized by an injection of $6-10 \mathrm{mg} / \mathrm{kg}$ of Ketamine $\mathrm{HCl}$. Ketamine is a short-acting, dissociative anaesthetic which has only a minor and transient effect upon the neuromusculature (KURODA and MCNAMARA, 1972). The anaesthetized monkey was then placed in a soundproof, electrically-shielded chamber and chaired in a primate-restraining device especially designed for electromyographic procedures (MCNAMARA, 1973). The head of the animal was oriented in a fixed position by means of a Plexiglas headholder to allow for normal jaw function in an unanaesthetized condition.

Pairs of monopolar platinum electrodes were inserted aseptically into the anterior temporal, posterior temporal, masseter, orbicularis oris and the suprahyoid group of muscles including the anterior digastric, mylohyoid and geniohyoid. The latter three muscles were analysed as a single muscle group because of the difficulty in separating them anatomically during electrode placement. The anterior heads of the two digastric muscles in Macaca mulatta are not separated into discrete bellies, as is typical in man. Rather, the anterior heads fuse at the midline, and, in addition, often 
blend with fibres of the mylohyoid muscle (Bosma, 1967; Howell and STraus, 1969). Both heads of the lateral pterygoid were also monitored, using two $25 \mathrm{~mm}$ Teflon insulated needle electrodes which were passed extraorally through the sigmoid notch into one of the heads of the lateral pterygoid muscle. MCNAMARA (1973) has described separate and independent functions of the superior and the inferior heads of this muscle. All records were taken from the musculature on the left side. The EMG recordings were made on Kodak Linagraph direct-print paper using a Beckman Type $R$ Dynograph amplifier and a Honeywell Model 1108 Visicorder.

After verification of electrode placement, the animal was left isolated in the soundproof room for a minimum of 30 additional minutes or until the effects of the anaesthetic on the neuromusculature had dissipated. Three types of swallows were then studied in the monkey: salivary, water and masticatory. Recordings of the unprovoked salivary swallow were initiated while the animal was still in isolation. The investigator then entered the soundproof chamber, and generated water-swallows through the administration of $0.5 \mathrm{ml}$ tap-water by syringe. The masticatory-swallow was recorded during or at the conclusion of chewing sequences elicited by feeding the animal bits of apple or sugar. Salivary swallows were also monitored during this portion of the recording session.

As no recordings of occlusal contacts were made, it was difficult to determine absolutely whether or not a particular swallow was "teeth together" or "teeth apart", classifications often used in human studies (RIX, 1946). However, the direction of mandibular movement observed during the swallow was noted. Also, the terms "unconscious" swallow and "command" swallow were not used in the present study, due to the obvious difficulties in communication with the experimental animal.

\section{Patterns of muscle activity}

\section{RESULTS}

In the various types of swallows (salivary, water and masticatory), three patterns of muscular activity could be identified. The relative occurrence of these patterns varied with the swallow type.

Pattern $A$. Activity was observed primarily in the suprahyoid muscle group and in the superior head of the lateral pterygoid muscle (Fig. 1a, Table 1). The suprahyoids usually fired concurrently with the lateral pterygoid in a well-circumscribed burst of activity for 250-350 msec. No elevator activity was evident, except for a few isolated

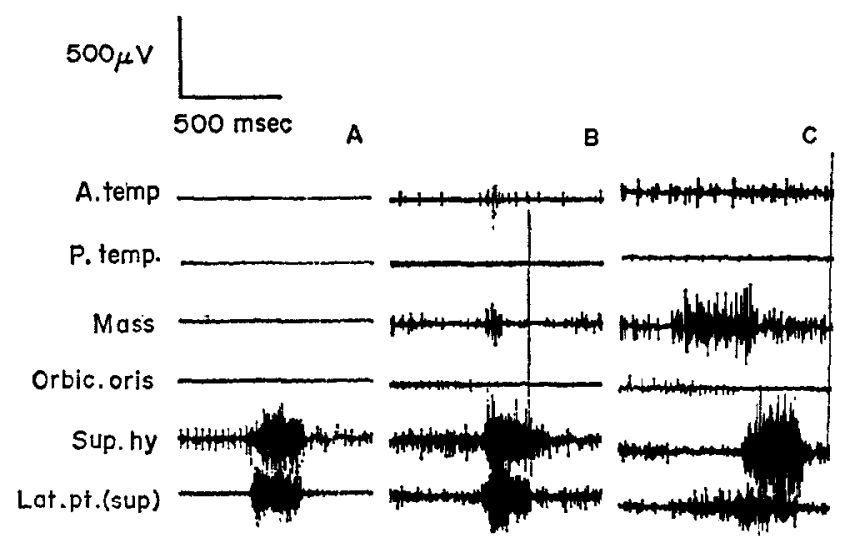

FIG. 1. Patterns of muscular activity during deglutition: (A) concurrent suprahyoid and lateral pterygoid firings with minimal or no elevator activity, (B) initiation of elevator activity concurrently with suprahyoid and lateral pterygoid function, (C) initiation of elevator and lateral pterygoid activity precedes suprahyoid burst. (Recording speed $100 \mathrm{~mm} / \mathrm{sec}$.) 
TABle 1. SWALLOW PATTERNS IN Macaca mulatta

\begin{tabular}{|c|c|c|c|c|c|c|}
\hline \multirow{2}{*}{$\begin{array}{l}\text { Swallowing } \\
\text { pattern }\end{array}$} & \multirow{2}{*}{$\begin{array}{l}\text { Suprahyoid } \\
\text { musculature } \\
\text { (msec) }\end{array}$} & \multicolumn{2}{|c|}{$\begin{array}{l}\text { Superior head of } \\
\text { lateral pterygoid }\end{array}$} & \multicolumn{2}{|c|}{ Elevator musculature } & \multirow{2}{*}{$\begin{array}{c}\text { Jaw } \\
\text { movement }\end{array}$} \\
\hline & & Duration & Timing & Duration & Timing & \\
\hline $\mathbf{A}$ & $250-350$ & $200-300$ & $\begin{array}{l}\text { Concurrent or } \\
\text { slightly preceding }\end{array}$ & $\begin{array}{l}\text { None or } \\
\text { few spikes }\end{array}$ & $\begin{array}{l}\text { Concurrent } \\
\text { if active }\end{array}$ & \multirow{3}{*}{$\begin{array}{l}\text { Stable or } \\
\text { slightly elevated } \\
\text { (teeth apart) } \\
\text { Elevation } \\
\text { (teeth?) } \\
\text { Elevation } \\
\text { (teeth together) }\end{array}$} \\
\hline $\mathbf{B}$ & $300-350$ & $200-350$ & Concurrent & $100-200$ & Concurrent & \\
\hline C & $300-350$ & $200-650$ & Preceding & $200-650$ & Preceding & \\
\hline
\end{tabular}

spikes which occasionally occurred at the onset of suprahyoid activity in the masseter or anterior temporal muscles. The inferior head of the lateral pterygoid was inactive in this pattern, and in the other two patterns of swallowing. In pattern $A$ swallows, the mandible was either stable or slightly elevated and it appeared that the teeth did not occlude.

Pattern $B$. The activity of the suprahyoids was either similar to that observed in pattern $A$ or the burst of activity was longer in duration by a maximum of $50 \mathrm{msec}$. In this type of swallow, the firings of the temporal and masseter muscles were greater in both duration and amplitude than in pattern $A$. The temporal muscle, the masseter muscle and the superior head of the lateral pterygoid muscles fircd concurrently with the suprahyoids, with elevator activity lasting up to $200 \mathrm{msec}$ (Fig. 1B). The lower jaw was raised and the teeth often appeared to occlude.

Pattern $C$. Elevator and superior-head activity preceded the suprahyoid burst, occasionally by as much as $450 \mathrm{msec}$ (Fig. 1C). The mandible was raised and the teeth apparently occluded hefore the reflex phase of deglutition was initiated.

\section{Occurrence of muscle patterns}

The relative occurrence of these muscle patterns varied with the type of swallow (Fig. 2). About 60-70 per cent of the salivary swallows were of pattern $A$, in which little or no elevator activity was observed. The remainder were of pattern $C$, except for the occasional occurrence of swallows with concurrent elevator activity (pattern

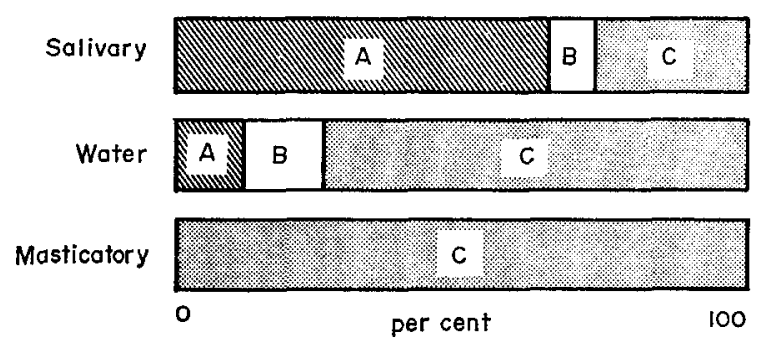

FIG. 2. Relative distribution of patterns of muscle activity during deglutition according to swallow type. 
$B$ ). Swallows associated with masticatory sequences were entirely of pattern $C$. All three swallow patterns were elicited with the administration of water. Most water swallows were of pattern $B$ and $C$, but about 10-15 per cent were characterized by minimal or no elevator activity (pattern $A$ ). However, both the relative occurrence of each pattern and the specific muscle sequence within each pattern varied with the individual animal.

Most of the variation in the patterns of muscle activity during the swallow involved the activity of the elevator muscles and the activity of the superior head of the lateral pterygoid. The elevator musculature was usually more active in masticatory than in water and salivary swallows. However, the burst activity in the suprahyoids in patterns $B$ and $C$ swallows was of a relatively constant duration in each monkey. The average range of variation was only $50 \mathrm{msec}$ (Table 1). Only in the salivary swallow, recorded while the animal was isolated, was the suprahyoid activity slightly reduced.

Age-related differences were observed in the relative roles of the elevator muscles. The dominance of the anterior temporal in young animals gradually changed to masseter dominance in the more mature monkeys. However, the specific duration of elevator activity was more characteristic of a particular animal than of any age group.

\section{DISCUSSION}

Doty and Bosma (1956), in the electromyographic analysis of deglutition in dogs, cats and monkeys, state that swallowing is initiated by the abrupt onset of activity in specific muscles of the rostral pharynx. They term these muscles the "leading complex" of the swallow. This muscle synergy is essential to the swallow, with participation of these muscles always in a rigid temporal sequence. Such essential muscles as the mylohyoid and geniohyoid (two of the muscles of the suprahyoid group monitored in the current study) do not appear to be susceptible to proprioceptive or exteroceptive feedback or conditioning (DoTY and BosMA, 1956; STOREY, 1967). In the present study, the suprahyoid muscle group, acting together with the superior head of the lateral pterygoid muscles, demonstrated a well-circumscribed burst of activity which was characteristic of the swallow, regardless of the particular muscle pattern involved. The duration of suprahyoid activity was relatively constant in each monkey. Only during periods of isolation was there a slight decrease in the duration of suprahyoid activity. Doty and Bosma (1956) also note a similar decrease in the duration of the activity of the lead muscles of the swallow when the animal is not aroused. However, they report that the sequence of muscle action is not altered by the variation in overall duration of muscle action.

In contrast to the findings of the current study, DoTY and BoSMA (1956) recorded no swallowing activity in the masseter or temporal musculature in monkeys. This discrepancy in findings may be explained by considering the elevator muscles as musculature which is supportive to the swallow. The supportive swallowing musculature includes those muscles involved in deglutition which do not follow a rigid time sequence. These muscles may or may not participate in any given swallow, or may fire at variable durations prior to or at the initiation of activity of the essential 
swallowing musculature. The supportive musculature is more sensitive to sensory feedback and thus illustrates more variation in functional activity.

The supportive musculature monitored in the present study includes the masseter muscle, the anterior and posterior portions of the temporal muscle, and the superior head of the lateral pterygoid muscle. These muscles can be affected by both anaesthesia (Kuroda and MCNamara, 1972), and changes in the postural position of the head (Lund, Nishiyama and Møller, 1970). Activity is necessary in these muscles to stabilize or raise the mandible during deglutition when the animal is in an upright position.

Variation in the activity of the temporal muscle, the masseter muscle and the superior head of the lateral pterygoid muscle is evident even when the factors of anaesthesia and head position are held constant. The pattern of muscle activity during deglutition also appears to be related to the particular bolus which initiates the swallow. For example, minimal elevator activity is noted during salivary swallows, while elevator function always precedes the suprahyoid burst during swallows associated with mastication. However, variations in elevator function also occur during swallows in which the same type of bolus is consumed (i.e. saliva, water). In these instances, the size, shape and consistency of the bolus or the precise circumstances under which the bolus is introduced may also influence the activity of the supportive musculature.

Despite the variation in the patterns, swallowing activity in Macaca mulatta under the present experimental conditions shows less variability in the duration and patterns of muscle function than does that of man. This may be partially due to the fact that it was possible to control the experimental conditions of the current study more than is usually possible for clinical studies of man. It can also be postulated that this reduced variability may be due in part to a reduction in psychic input of which has been shown in man to influence electromyographic recordings of the orofacial muscles (e.g. Moyers, 1950; Perry, 1954; Garnick and Ramfjord, 1961).

As mentioned earlier, occlusal contacts were not monitored during this investigation and thus a precise determination of "teeth together" and "teeth apart" swallows was not possible. However, the direction of mandibular movement during deglutition was noted. The mandible was stabilized or raised during all patterns of swallowing activity, not lowered as has been observed in some infantile swallows in man (MoYERs, 1964b).

Acknowledgments-We wish to thank Dr. M. LAWRENCE and Dr. R. E. STONE of the Kresge Hearing Research Institute for providing the electromyographic facilities used in this study. Editorial assistance was furnished by Mrs. Ruth Bigio and Mrs. KATHERINE RibBENS. The illustrations were provided by Mr. W. L. Brudon and Miss Sally Everhardus. This research was supported, in part, by United States Public Health Service Grants DE-02272 and DE-03610.

Résumé-Les types d'activité musculaire pendant la phase buccale de déglutation ont été analysés chez trente trois Macaca mulatta. La salive l'eau et le nombre de déglutitions masticatoires ont été étudiées. L'activité du groupe musculaire sushyoidien est relative- 
ment constante. Cependant trois types d'activité sont identifiés au niveau des autres muscles masticateurs. Dans le premier type, les sushyoidiens fonctionnent simultanément avec la partie supérieure du ptérygoidien latéral, avec peu ou pas d'activité élévatrice. Dans le second type, le temporal, le masséter et la partie supérieure du ptérygoidien latérale fonctionne en même temps que les sus-hyoidiens. Dans le troisième type, l'activité du ptérygoidien latéral et du muscle élévateur précède l'activité sushyoidienne. Ce type d'activité musculaire varie selon le type de déglutition.

Zusammenfassung-Bei 33 Macaca mulatta-Affen wurden die Abläufe der Muskelaktivität während der oralen Phase des Schluckens untersucht. Hierzu gehörte das Schlucken von Speichel, Wasser und zerkauter Nahrung. Die Aktivität der suprahyoidalen Muskelgruppe war relative konstant. Dagegen ließen sich bei den anderen Kaumuskeln 3 Aktivitätstypen festellen. Beim ersten Typ funktionierten die suprahyoidalen Muskeln gewöhnlich zugleich mit dem oberen Kopf des lateralen M. pterygoideus mit wenig oder gar keiner Aktivität der Schließmuskulatur. Beim zweiten Typ funktionierten die Mm. temporalis, masseter und der obere Kopf des lateralen M. pterygoideus zugleich mit den suprahyoidalen Muskeln. Im dritten Falle trat die Aktivität der Schließmuskeln und der lateralen M. pterygoidei der suprahyoidalen Aktivität varaus. Die verschiedenen Typen der Muskelaktivität unterschieden sich nach Art der untersuchten Schluckbewegungen.

\section{REFERENCES}

Beevor, C. E. and Horsley, V. 1888. Note on some of the motor functions of certain cranial nerves (V, VII, IX, XI, XII) and of the three first cervical nerves in the monkey (Macaca sinicus). Proc. R. Soc. Lond. Ser. B. 44, 269-277.

Busma, J. F. 1956. Myology of the pharynx of cat, dog, and monkey with interpretation of the mechanism of swallowing. Ann. Oto. Rhino. Laryng. 65, 981-992.

Cleall, J. F. 1965. Deglutition: a study of form and function. Am. J. Orthodont. 51, 566-594.

Doty, R. W. 1951. Influence of stimulus pattern on reflex deglutition. Am. J. Physiol. 166, 142-158.

DoTY, R. W. 1968. Handbook of Physiology, Section IV: Alimentary Canal (edited by CoDE, C. F.), Chap. 92, pp. 1861-1902. Am. Physiol. Soc., Washington, D.C.

Doty, R. W. and Bosma, J. F. 1956. An electromyographic analysis of reflex deglutition. $J$. Neurophysiol. 19, 44-60.

Doty, R. W., Richmond, W. H. and Storey, A. T. 1967. Effect of medullary lesions on coordination of deglutition. Expl Neurol. 17, 91-106.

Findlay, I. A. and Kilpatrick, S. J. 1960. An analysis of myographic records of swallowing in normal and abnormal subjects. J. dent. Res. 39, 629-637.

FLeTCHer, S. G. 1971. Patterns of Orofacial Growth and Development (edited by MORRIS, H. L.), Chap. 6, pp. 66-88. Am. Speech Hearing Ass., Washington, D.C.

Garnick, J. and Ramfjord, S. P. 1962. Rest position. J. Prosth. Dent. 12, 895-911.

Hanson, M. L. 1967. Some suggestions for more effective therapy for tongue thrust. $J$. Speech Hearing Dis. 32, 75-79.

Howell, A. B. and Straus, W. L., JR. 1969. The Anatomy of the Rhesus Monkey (edited by Hartman, C. G. and StRaus, W. L., JR.), Chap. 7, pp. 89-175. Hafner, New York.

HRYCYSHYN, A. W. and BasmaJian, J. V. 1972. Electromyography of the oral stage of swallowing in man. Am. J. Anat. 133, 333-340.

KaHN, R. II. 1903. Studien über den Schluckreflex. I. Die sensible Innervation. Archs Physiol. Suppl. $27,386-426$.

Kuroda, T. and McNamara, J. A., JR. 1972. The effect of ketamine and phencyclidine on muscle activity in non-human primates. Anesth. Analg. 51, 710-716.

Lund, P., Nishiyama, T. and Møll.er, E. 1970. Postural activity in the muscles of mastication with the subject upright, inclined, and supine. Scand. J. dent. Res. 78, 417-424.

McNamara, J. A., JR. 1973. Restraint of monkeys for craniofacial research. J. dent. Res. 52, 183.

McNamara, J. A., JR. 1973. The independent functions of the two heads of the lateral pterygoid muscle. Am. J. Anat. in press.

Miller, F. R. and SherRington, C. S. 1916. Some observations on the bucco-pharyngeal stage of reflex deglutition in the cat. Q.J. exp. Physiol. 9, 147-186. 
MoYers, R. E. 1950. An electromyographic analysis of certain muscles involved in temporomandibular movement. Am. J. Orthodont. 36, 481-515.

MOYERs, R. E. 1964a. Tongue problems and malocclusions. In: The Dental Clinics of North America, pp. 529-539. Saunders, Baltimore.

Moyers, R. E. 1964b. The infantile swallow. Trans. Europ. Orthodont. Soc. 40, 180-187.

Rix, R. E. 1946. Deglutition and the teeth. Dent. Rec. 66, 103-108.

RYLANT, P. 1943. Contribution à l'étude des variations du contrôle réflex de l'activité respiratoire par les fibres sensibles du nerf vague. Archs intern. Pharmacodyn. 69, 45-113.

Storey, A. T. 1967. Symposium on Oral Sensation and Proprioception (edited by Bosma, J. F.), Chap. 3, pp. 84-97. Thomas, Springfield.

TULLEY, W. J. 1953. Methods of recording patterns of behaviour of the oro-facial muscles using the electromyograph. Dent. Rec. 73, 741-748.

Waller, A. and Prevost, J.-L. 1870. Étude relative aux nerfs sensitifs qui president aux phénomènes réflexes de la déglutition. Arch. Physiol. Norm. Pathol. 3, 185-197. 